\title{
Implementation of Team Project in "Foundation Treatment”Course
}

\author{
Gang Wei \\ Department of Civil Engineering, Zhejiang University City College, Hangzhou 310015, China \\ Email: weig@zucc.edu.cn
}

Received 2012

\begin{abstract}
Foundation treatment is required course of the architectural engineering direction of civil engineering specialty in Zhejiang university city college. For students' characteristics and the problems in teaching, learning the engineering education of CDIO model and reforming the assessment criteria and the form of homework, 18 extra-curricular additional projects and 14 curricular knowledge expansion projects were added in the curriculum. The capabilities of students on teamwork, civil engineering design, and communication were developed through teamwork. Through this educational reform and practice it, it won the praise of students
\end{abstract}

Keywords: CDIO Model for Engineering Education; Teamwork; Foundation Treatment

\section{Introduction}

Foundation treatment is a required course of the architectural engineering direction of civil engineering specialty in Zhejiang university city college, and it is also the key course of construction projects in our college. In the teaching process the following issues were found that: (1) Existing materials more content are main classic and sophisticated theory, so that it upgraded so slowly. But the new techniques and methods of foundation treatment continue to appear, so the textbook content can't satisfy students' needs for knowledge, and hasten to add new extra-curricular knowledge; (2) the students are lack of enthusiasm for study. If the teachers adopt the mode of teaching and "scripted" spoon-fed ground treatment knowledge to their students, it will make student lose interest in studying and lack of enthusiasm in learning. (3) Students' skills on teamwork, communication can't be developed under the traditional mode of teaching, but those abilities are very important parts of CDIO outline.

As the new techniques and methods of foundation treatment appearing, how to integrate existing curriculum content and collect the extra-curricular information which can be closely integrated with the engineering practice are crucial. After it, student can grasp the knowledge efficiently in the limited time, and also improve the students' enthusiasm for learning at the same time. In teaching practice, CDIO engineering education mode was learned and the teaching content were adjusted to supply the extra-curricular knowledge, expand curricular knowledge, and develop students' teamwork, communication capabilities by the form of team projects.

\section{Specific Reform Ideas}

It includes: (1) deepening supplementary items of extracurricular knowledge which is original of book report. Students hope to participate in the teaching actively in survey. So classroom teaching mode was reformed to change the mode used by the teacher lectures. Book report tem was hold in the classroom since 2009, which is done by students for reading report on the latest ground-based approach. Meanwhile, because the project needs spending time outside the course, it is equivalent to layout operations. Book report activities were held 10 times in 2009, 11 times in 2010, 12 times in 2011 totally. From the reflecting of school and students point of view, reporting activity is good and got warm welcome from students. The reporting activity will be added up to 18 times in 2012. First, decline the team number to reduce the students who fish in trouble water and allow more students came to present reporting; second, it enables students to understand latest ground-based processing technology related to course; (2) add curricular knowledge expansion projects. Students express their textbook homework is too boring and few students preview the course which suns to 14 times. So the expansion project of curricular knowledge was proposed instead of homework. It is also a form of teamwork, and requires students preview textbooks courseware in advance to supply the knowledge and case which textbooks doesn't not say.

The corresponding outline of the civil engineering professional CDIO is "Civil Engineering Major excellent engineer training program”. Specific training capacity and weight for this course after the reform includes: (1) the ability to query information or electronic documents (2 weight); (2) explore the field of civil engineering, new problems, new development actively (1 point); (3) cultivate teamwork and collaboration (3 points); (4) having the organization, coordination and leadership (0.5 points); (5) be good at the technical division of labor and cooperation, and common goals (0.5 points); (6) having the awareness and ability of the exchange and communication (1 points); (7) having the ability to communicate the use of writing, graphics, electronics and multimedia (2 points); (8) adept at verbal expression, to organize reports and meetings to exchange (1 point); (9) master of civil engineering design principles, processes and methods to make comprehensive use of civil engineering expertise ( 5 points) where the full weights is 5 points. 
After the reform, the total score of the "foundation treatment course" is composed as follows: (1) named and usually performance, accounting for 20 points; curricular supplementary item (2), accounting for 10 points; (3) extracurricular supplementary item, accounting for 30 points; (4) final papers, accounting for 40 points.

\section{Specific Rules for the Operation}

\section{Supply Extra-curricular Knowledge Item}

The specific steps are as follows:

(1) Determine the subject. Not to repeat the same time keep up the pace, choose a new foundation approach, to enable students to broaden their horizons and expand their knowledge and teaching materials. Determine the following topics: 1 ) root piles; 2) the length of pile composite foundation (pile of twin); 3) low-strength concrete piles; 4) squeezed branch pile; 5) micro-piles; 6) screw piles; 7) Y-type and X-immersed tube pile; 8) cased Secant Pile; 9) broken Stone Pile (plasma solid gravel pile); 10) cast thin-walled cylindrical piles (piles); 11) bored pile grouting technology; 12) nail-shaped and bi-directional soil cement mixing pile; 13) of SMW method; 14) Drainage DJM; 15) Blasting; 16) low-temperature freezing (low temperature brine and liquid nitrogen The); 17) manual digging pile; 18) bubble mixed light soil.

Arrange a specific time for each subject in a specific week at the same time. Extracurricular project subject arrangements need to consider the convergence of content and teaching materials. For example, "the length of the pile composite foundation (rigid-flexible combinations pile)" should be reported in the second chapter of the composite foundation theory is finished; "outing pile of rubble (pulp solid gravel pile)" in the fourth chapter of the deep dense: cement fly ash (CFG pile gravel pile), lime pile and the soil pile finished report; cement mixing method finished nail shape with bi-directional soil cement mixing pile of SMW method should be reinforced in chapter 6 chemical after the report.

(2) Grouping of students. Base on the elective list, teachers press 2 to 4 pairs are grouped into 18 groups. Students need to replace the group may agree, and tell the teacher. Then select the team leader by the group members themselves, reported to the teacher. Finally, the subject of each group needs to determine the specific reporting time by the head of the ballot. Then
Fill in the information in Table 1.

(3) Tell students about the project implementation methods, requiring a clear member of the division of labor.

Teacher uses an example to enable students to understand the report content before a case such as the plastic casing concrete piles (TC pile) steps. Students get together, first discuses topics, and then gather, collate information, produce PPT, write text. The report normally includes: the principle of this method (the mechanism), scope, design methods, construction techniques, construction procedures, machinery and equipment, construction notes, laboratory and field tests, projects and methods, quality management and inspection methods, cite specific engineering application. Meanwhile, we must answer the following questions: 1) why is the technology to make; 2) technological innovation point; 3) advantages and disadvantages of the technology; 4) the scope of application of this technology.

Finally turn over the results of including text and PPT, the text format "Rock and Soil Mechanics" papers template layout, requiring the complete content, format, complete content of the PPT requirements, and beautifully produced.

Members of the group came to power using the PPT forms (auxiliary video or animation) make a report, display text, to introduce students to the latest ground-based approach, the time control in about 10 minutes. Introduced after the students, teachers ask questions, teachers and students together to discuss. Teachers finally conclude our discussion of control in about five minutes. The whole event time is controlled in about 15 minutes.

Specific division of the group 3 before class to find information, write the text, the production of the PPT. One person is responsible to explain the theoretical part, and a person responsible for explaining actual case, one person is responsible for answering the questions of teachers and students in class. (If the team is the group of four people, two people responsible for displaying the remaining two people assigned by the instructor to answer questions; if the team is a 2 group, 2 per capita to participate in the show, one of whom is also responsible for answering questions).

(4) Assessment methods. The team project is the most difficult assessment methods, such as inappropriate and will cause students to muddy the waters into a small number of people doing other people robbing, while individual scores are difficult to distinguish.

Table 1.

The list of extracurricular project team and scores table.

\begin{tabular}{cccccccc}
\hline Sequence & Title & Leader, team members & Report time/week & Teacher score & Group score & Score of other team & Final score \\
\hline 1 & & & & & \\
2 & & & & \\
\hline
\end{tabular}

Supply items of the extra-curricular knowledge out of 30 points. Scores of specific composition and scoring criteria are as follows: text accounted for 10 points; PPT production accounted for 10 points; speech and answer questions accounted for 10 points. Specific score consists of three parts: 1) teachers' ratings, the weight of $0.4 ; 2$ ) team self-assessment, a weight of 0.3 , average limit ( $\leqslant 24$ points), while the highest score lowest score difference is not less than 5 minutes fill in table 2 by the team members, after consultation, sign and turned over by the head of the teacher; 3 ) group peer assessment, weight of 0.3 .
Each member of the other groups, complete table 3, the playing team points, signature, and then taken by the head of the average, and paid teachers. In this way, you can get the team average, combined with the team self-assessment, and you can get the scores of each team member. For example: the average score of 24 points and a team self-assessment, head of the 27 points the rest of the team 24 points, 21 points, respectively. Teacher's score of 20 points, peer assessment of the other groups were divided into 22 points. Weights can be the team's average score: $20 * 0.4+24 * 0.3+22 * 0.3=21.8$. The average point 
of team self assessment is lower than 2.2 points, so the head of a score of $27-2.2=24.8$ other team members were 21.8 points, 18.8 points. The highest score of students will not exceed 30 minutes.

Teachers give students about to clear the entire process of project operation in the first class, and all students are divided group, a clear report on the subject to report on time. Each item in the next class on the publicity results, shown in Table 1, so that students know their results. The last lesson, summarize the average ranking of all teams, to identify the best team (top three) in recognition to motivate students to compete.

\section{Curricular Knowledge Expansion Projects}

Its objective: according to the teaching materials by students looking for extra-curricular material as a supplement other than the teacher lectures to deepen students' understanding of course content knowledge. Requirements prior to download courseware learning, not allowed repeating with the courseware.

The specific operational procedures are as follows:

(1) Determine the subject. Arrange it for a total of 14 times, specific topics are as follows: 1) 3rd class-replacement; 2) 4th class-dynamic compaction; 3) 5th class- rubble pile; 4) 6th class-pulverized cement gray gravel pile (CFG pile); 5) 7th class- heap load preloading method; 6) 8th class-the vacuum preloading method; 7) 9th class -soil cement mixing method; 8) Section 10 sub-class-high pressure jet grouting method; 9) 11th class - grouting method; 10) 12th class-civil synthetic materials; 11) 13th class-reinforced earth retaining wall; 12) 14th class-anchor and soil nailing; 13) 15 classes-Underpinning technology; 14) 16th class - rectification technology.

(2) Grouping of students. Teachers first elective list, arrange 3 to 5 pairs, a total of 14 groups, Leader elected by the students themselves. Each subject prepared by the three groups. The group order to determine the subject of each group. Each team for a semester prepares three questions in this way. Give students a clear title and report time listed in Table 4.

(3) The division of labor and assessment methods. Specific reporting content, the process is similar to the extra-curricular knowledge supplementary item, with emphasis on actual case. The students work together turned over to the group before class text and PPT.

Classroom time is limited, the general arrangement of a group report, so the head of the drawing of lots to determine which group came to power before class. Score from the team self-assessment (weight 0.4) and teachers' ratings (the weight of
0.6) composition. The team self-assessment is done by the team members signature, and turned over by the group head (see Table 5), and average is limited (to $\leqslant 8$ ), and the highest score lowest score difference of not less than 2 minutes.

Teachers, students turned over to the PPT and text, as well as the coming to power of the performance of the group, given the scores. Combined with the project self-assessment, take the average final score of the 3 curricular items project team from the results of each member.

\section{Usage of BB Platform}

Teachers and students use the BB platform together. Teachers upload before a week classes. Extra-curricular, curricular projects are uploaded the final students grouping list in a timely manner. Student uploads achievement timely each time after class. Students advance through the BB platform download courseware, preview and make appropriate curricular project courseware, you can download and learn from others' results.

\section{Other Instructions}

(1) The teaching schedule is ready, and arranges the items of each class before the first class.

(2) The first lesson is critical, the project should be explained clearly points to the students group to elect the leader, determined by the head of the ballot title and reporting time. Give good information to each head of hair staple. Extra-curricular group include: teaching schedule, Table 2, Table 3, the project implementation manual (extracurricular); curricular team includes: Table 4 and Table 5, the project implementation manual (class within).

Table 2.

Teams self assessment form (Extra-curricular projects).

\begin{tabular}{|c|c|c|c|}
\hline Group number & Score & Average mark & Signature \\
\hline Group leader & & & \\
\hline
\end{tabular}

Table 3.

Other teams score table (set of ratings).

\begin{tabular}{|c|c|c|c|}
\hline Group number & Score & Average mark & Signature \\
\hline Group leader & & & \\
\hline
\end{tabular}

Table 4.

Curricular project team list and scores table.

\begin{tabular}{|c|c|c|c|c|c|}
\hline Sequence & Leader, team members & $\begin{array}{l}\text { Reporting time } \\
\text { ( weeks )- Title }\end{array}$ & Teacher score & Team self-ratings & The final results \\
\hline 1 & $\begin{array}{l}\text { Group leader: } \\
\text { Group member: }\end{array}$ & $\begin{array}{l}3 \text {--- Replacement } \\
7 \text {---Preloading } \\
12 \text {--- Geosynthetics }\end{array}$ & & & $\begin{array}{l}\text { Group leader: (_score), group member: } \\
\text { (_score), group member: (_score) }\end{array}$ \\
\hline
\end{tabular}

Table 5.

Team self-evaluation form (Curricular projects).

\begin{tabular}{cccc}
\hline Group number & Score & Average mark & Signature \\
\hline Group leader & &
\end{tabular}


(3) Implementation of the project's biggest challenge is the control of teachers' time. From the time a lot of teaching materials, how to accurately control the time has become a big problem. Accounted for a class project for the allocation of time, the general content of textbooks, cases accounted for a class, named time can be flexible. Don't arrange extra-curricular projects for much cycles of the curriculum.

(4) The subject of teaching materials after the reform before the operation about one hour each time, a total of 15 times, namely 15 hours. After the reform, each student needs to do four projects (an extra-curricular and curricular), which has less time before the reform.

\section{Conclusions}

The student response is very good since implementation of project. There were 36 people came to report extra-curricular project for each class, and 14 people came to power reporting in the curricular project, so almost all students have the opportunity came to power exercise. The following students' attention are much focused when the students speech on the stage. The activities not only improve students' learning initiative and classroom attention, broaden students' knowledge and understanding of the latest methods of ground treatment, but also exercise the student's teamwork, independent learning, and writing text, the production of PPT and communication ability.

\section{REFERENCES}

Wei Gang, Zhang Shimin, Wei Xinjiang. The reform of teaching and practice foundation treatment curriculum. Journal of Shanghai Polytechnic College of Urban Ma, vol. Supp.1: 99-100, 2009. (In Chinese)

Translated by Gu Peihua, Shen Minfeng, Lu Xiaphua. Re-understanding of the engineering education - International CDIO training mode and methods. Beijing: Higher Education Press, 2009. (In Chinese) 